\section{New defences}

Professional Dental Supplies on stand J12 will be launching the Hydrojet cleansing decontaminator. It uses HydroSol, which is a unique micro-biocidal solution that ensures instruments are decontaminated to the highest possible standards.

The company will also be showing its range of barrier products which can minimise cross-infection. It claims that the products can protect all the equipment in the dental surgery, such as awkward handpiece assemblies, curing lights, trays and $\mathrm{x}$-ray heads.

Dental chairs can be easily covered at a low cost, offering a timesaving alternative to cleaning and disinfection of surgery equipment and surfaces between patients.

Reader response number 73

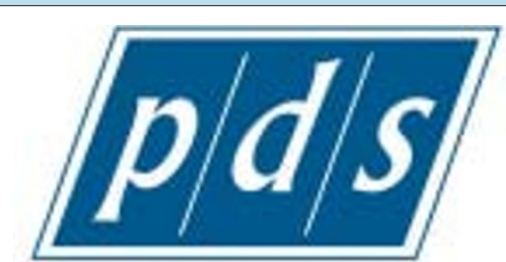

Professional Dental Supplies

\section{Finance fitness}

The Dentist's Provident Society will be exhibiting at stand A02 where visitors can find out about income protection and personnel sickness cover.

Sickness and accident benefits include a maximum weekly benefit (based on a six day working week) of $£ 1200$, up to 75 per cent of earnings lost through incapacity. There is no waiting period as sickness benefit is paid from the first full day of incapacity. Regardless of how many claims are made, subscriptions are unaffected and membership continues until the age of 60 unless cancelled by the subscriber.

Authorised and regulated by the Financial Services Authority, visit www.dpsltd.co.uk for more details.

Reader response number 76

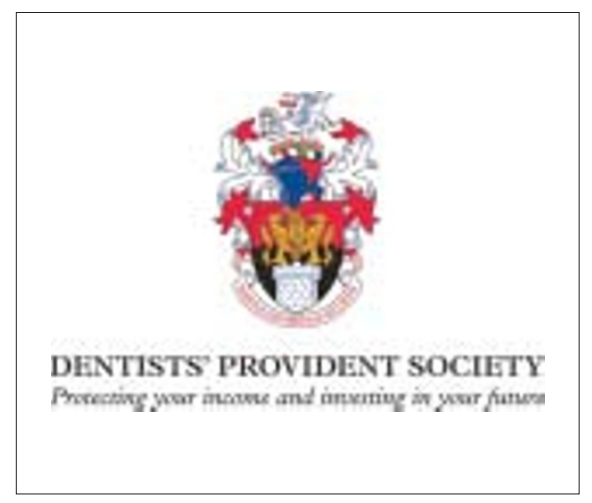

\section{Orthodontic ranges}

TOC Dental will be showing their product range which includes new Mystique, the latest in aesthetic brackets which has a metal-free glazed slot.

The company will also be showing InOvation ' $R$ ', a ligature-free bracket.

Also on display will be Reveal plaque indicating gel which discloses plaque, clearly indicating the areas where toothbrushing has not been effective.

Reader response number 74
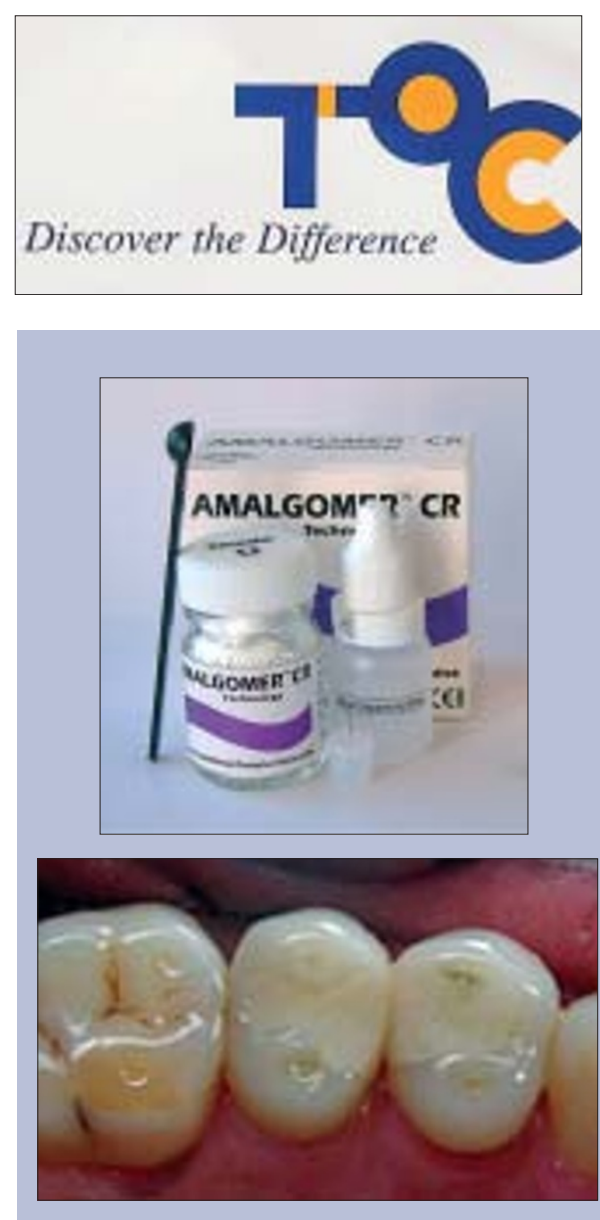

\section{Complete range on offer}

Oraldent will be launching Atridox on stand J11, which is for use in adults with chronic periodontitis at sites with probing depths of $5 \mathrm{~mm}$ or more, as an adjunct to conventional non-surgical management of periodontal disease.

It will also be showing Gengigel, a biotechnologically produced form of hyaluronan which can be used to aid mucosal healing due to any inflammatory or traumatic condition of the gingival tissue, such as gingivitis, periodontitis, aphthous ulceration, tooth extraction or post-surgical recovery.

In addition the Natural Dentist range will be on display. The range includes a variety of herbal mouth and gum rinses and herbal toothpastes that have been proven to kill bacteria, reduce gingivitis and bleeding gums.

The products contain 100 per cent natural ingredients, do not stain and are alcohol and sugar free.

Reader response number 78

\section{Oral healthcare

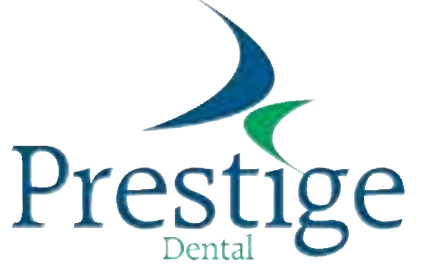

Visitors to both of Prestige Dental's stands at K08 and N15 can experience first hand the company's oral healthcare products, including water irrigators, electric tooth brushes, an electric flosser and electric travel brushes.

Reader response number 75

High resistance

Amalgomer $\mathrm{CR}$ posterior restorative is new from Advanced Healthcare, on stand G04. It has a compressive strength combined with unique ceramic reinforcement for durability and high radiopacity.

The company claims it has resistance to fracture or cracking and the high modulus allied to chemical adhesion to the tooth structure ensures low interfacial stresses.

Also from the same company is Amalgomer aesthetic anterior restorative. It is available in seven accurately matched Vita shades; A1, A2, A3, A3.5, B2, B4 and C3.

According to the company it has good translucency for highly aesthetic results. Wear and erosion resistance are also high making the product able to withstand all the stresses of the oral environment Reader response number 77

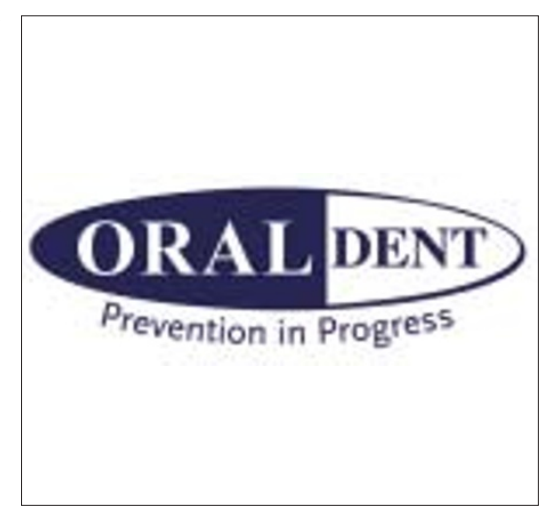

